\title{
Effects of Austenite Conditioning and Hardenability on Mechanical Properties of B-Containing High Strength
}

\section{Steels}

\author{
Chang-Sun LEE, Wung-Yong CHOO
}

Plate, Rod \& Welding Research Group, Technical Research Laboratories, POSCO

\begin{abstract}
Direct quenching(DQ) has become widespread instead of conventional reheat quenching in order to obtain good mechanical balance of high strength steels in addition to productivity, energy savings, alloy savings, and weldability. It is well known that mechanical properties of $D Q$ steel can be changed by varying slab reheating temperature, finish rolling temperature, and cooling rate in addition to alloy composition. The effect of pancaking by controlled rolling at low temperatures on mechanical properties was investigated. The effect of pancaking depends on hardenability determined by alloy contents. Pancaking increased strength or toughness when alloy-determined hardenability is high. But pancaking decreased strength when alloy-determined hardenablity is low.
\end{abstract}

KEY WORDS: direct quenching, B-containing steel, high strength steel, austenite conditioning, hardenability, pancaking.

\section{Introduction}

In direct quenching and tempering (DQT) process, which is a kind of thermomechanical process, plates are direct quenched after rolling and tempered to obtain good mechanical balance of high strength steels. Before the advent of DQT process, high strength steels were manufactured by reheat quenching and tempering (RQT) process, in which plates are air cooled after rolling, austenitized, quenched, and tempered.

DQT process has higher productivity and energy efficiency than RQT process due to omission of austenitizing after rolling, and also higher alloy efficiency and weldability due to higher hardenability at the same composition. High hardenability of DQT process can be explained by austenite grain size, non-equilibrium segregation of alloying elements to grain boundaries, and sufficient solid-solutioning of carbide-forming and nitride-forming elements due to high heating temperature(1)

DQT process has more degree of freedom than RQT process in controlling austenite condition before quenching. Austenite condition can be controlled by changing slab reheating temperature and rolling schedule in DQT process, and by changing austenitizing temperature only in RQT process. Consequently, the mechanical properties can be changed widely by austenite conditioning in DQT process.

This study investigated the effect of pancaking before direct quenching on mechanical properties of high strength steels with various alloy-determined hardenabilities.

\section{Experimental Procedure}

5 heats with the compositions of various hardenability, shown in Table 1, were vacuum induction melted and cast as $50 \mathrm{~kg}$ ingot. Each ingot was heated to $1260^{\circ} \mathrm{C}$, rolled to a cross section of about $125 * 102 \mathrm{~mm}$ (width * thickness), and air cooled for sizing. Fig. 1 shows one example of rolling history. After dividing the slab, the first divided slab for direct quenching after hot rolling (HR/DQ) was finish rolled at $954^{\circ} \mathrm{C}$ to $13 \mathrm{~mm}$ of thickness with 7 rolling passes and water quenched. The second divided slab for direct quenching after controlled rolling (CR/DQ) was finish rolled at $843^{\circ} \mathrm{C}$ and water quenched. In CR/DQ process, the thickness was reduced to $20 \mathrm{~mm}$ from $102 \mathrm{~mm}$ by 7 passes at austenite recrystallization region and then reduced to $13 \mathrm{~mm}$ by 2 passes at non-recrystallization region of $871^{\circ} \mathrm{C}$ and $843^{\circ} \mathrm{C}$ for pancaking. The quenched plates were tempered at 204 and $3711^{\circ}$, respectively.

Table 1. Chemical compositions of steels(mass \%)

\begin{tabular}{|c|c|c|c|c|l|}
\hline Heat & A3 & A4 & E1 & Fl & \multicolumn{1}{|c|}{ Gl } \\
\hline $\mathrm{C}$ & 0.131 & 0.127 & 0.147 & 0.147 & 0.145 \\
$\mathrm{Si}$ & 0.51 & 0.49 & 0.25 & 0.24 & 0.25 \\
$\mathrm{Mn}$ & 1.34 & 1.32 & 0.87 & 0.89 & 0.089 \\
$\mathrm{Cr}$ & - & - & - & 0.58 & 0.59 \\
$\mathrm{Mo}$ & - & - & 0.252 & - & 0.233 \\
$\mathrm{Ti}$ & 0.016 & 0.030 & 0.017 & 0.017 & 0.017 \\
$\mathrm{Sol}-\mathrm{Al}$ & 0.030 & 0.039 & 0.019 & 0.027 & 0.038 \\
$\mathrm{~B}(\mathrm{ppm})$ & 70 & 8 & 21 & 18 & 10 \\
$\mathrm{~N}(\mathrm{ppm})$ & 20 & 130 & 40 & 90 & 70 \\
\hline
\end{tabular}

In order to evaluate the hardenabilities of each steels and the effect of pancaking on hardenability, continuous cooling transformation(CCT) tests were carried out using Gleeble 1500. Table 2 shows the CCT schedules to simulate HR/DQ and CR/DQ processes. CCT specimens were 
finally deformed at $950^{\circ} \mathrm{C}$ for $\mathrm{HR} / \mathrm{DQ}$ and $800^{\circ} \mathrm{C}$ for CR/DQ.

Tensile test was carried out with subsize specimen of ASTM E8-81 and toughness test with Charpy V-notch specimen of ASTM E23-82 at $-40^{\circ} \mathrm{C}$.

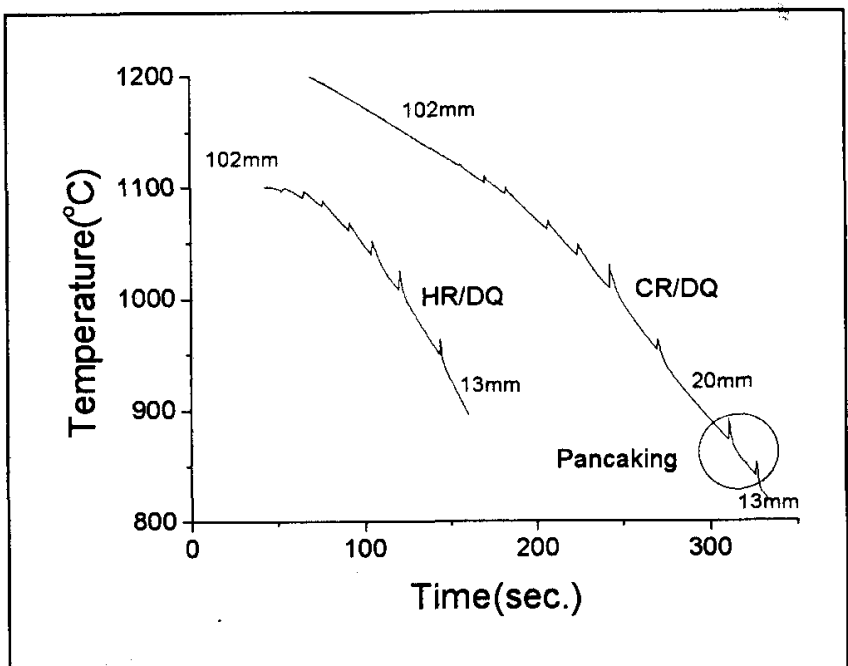

Fig. 1. Rolling history of G1 steel.

Table 2. CCT test schedule to simulate HR/DQ and CRDQ process.

\begin{tabular}{|l|l|}
\hline HR/DQ & $\begin{array}{l}10^{\circ} \mathrm{C} / \mathrm{s} \rightarrow 1200^{\circ} \mathrm{C} / 5 \mathrm{~min} \rightarrow 1^{\circ} \mathrm{C} / \mathrm{s} \rightarrow 1000^{\circ} \mathrm{C} / 20 \% \\
->11^{\circ} \mathrm{C} / \mathrm{s} \rightarrow 950^{\circ} \mathrm{C} / 20 \% \rightarrow 20 \mathrm{sec} \rightarrow \mathrm{Cool}\end{array}$ \\
\hline $\mathrm{CR} / \mathrm{DQ}$ & $\begin{array}{l}10^{\circ} \mathrm{C} / \mathrm{s} \rightarrow 1200^{\circ} \mathrm{C} / 5 \mathrm{~min} \rightarrow 1^{\circ} \mathrm{C} / \mathrm{s} \rightarrow 1000^{\circ} \mathrm{C} / 20 \% \\
->11^{\circ} \mathrm{C} / \mathrm{s} \rightarrow 800^{\circ} \mathrm{C} / 20 \% \rightarrow 20 \mathrm{sec}->\mathrm{Cool}\end{array}$ \\
\hline
\end{tabular}

\section{Result}

Fig. 2, in which open mark stands for HR/DQ and solid mark for CR/DQ, shows the effect of pancaking before direct quenching on mechanical properties of steel A3. Tensile strength increased by $360 \mathrm{MPa}$ from $950 \mathrm{MPa}$ to $1310 \mathrm{Mpa}$ in as-quenched state with little change of Charpy impact energy at $-40^{\circ} \mathrm{C}$ by applying pancaking. Tensile strength increased by $230 \mathrm{MPa}$ and $210 \mathrm{MPa}$ after tempering

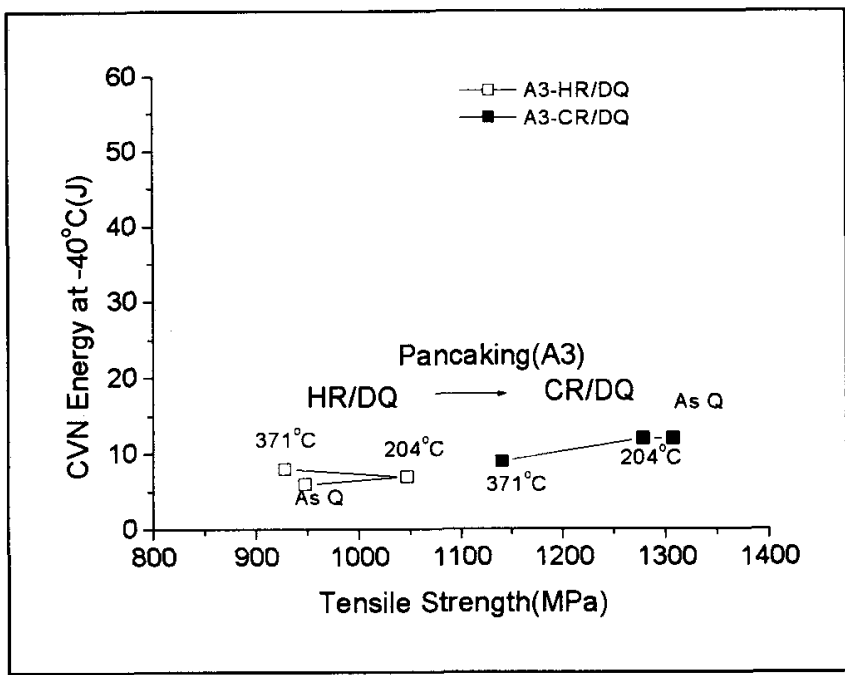

Fig. 2. Effect of pancaking before direct quenching on mechanical balance of $A 3$ steel

(C) 2000 ISIJ

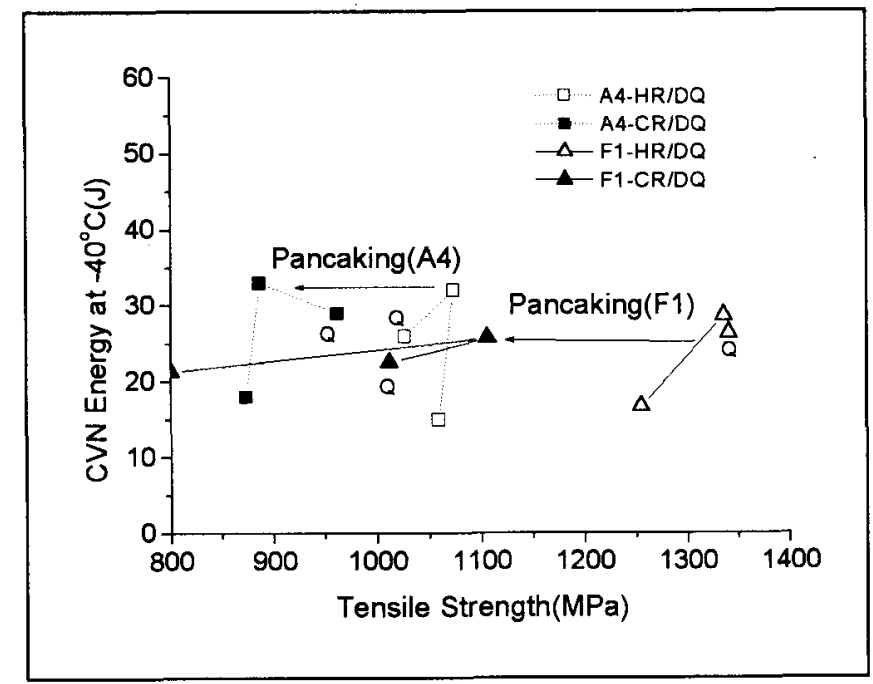

Fig. 3. Effect of pancaking before direct quenching on mechanical balance of A4 and F1 steel.

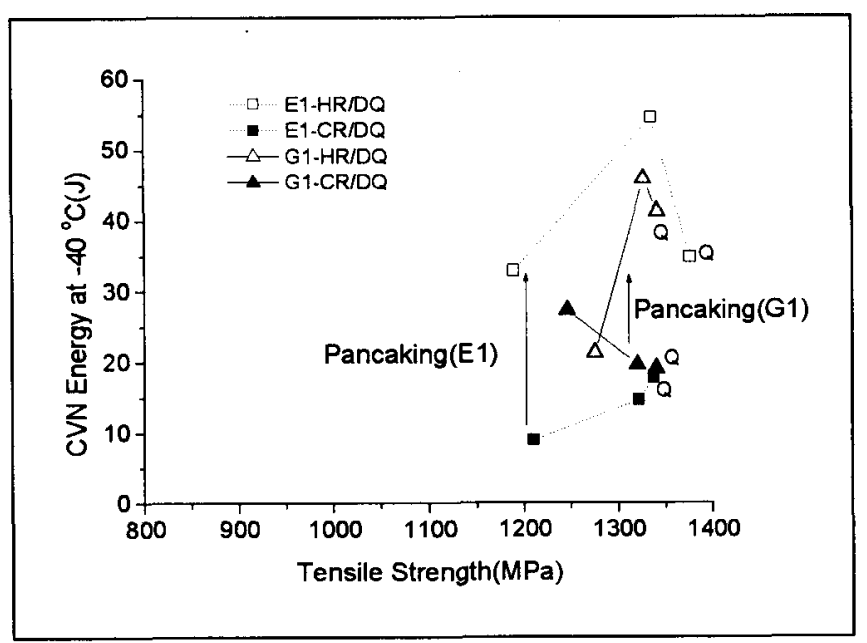

Fig. 4. Effect of pancaking before direct quenching on mechanical properties of $\mathrm{E} 1$ and $\mathrm{Gl}$ steel

at 204 and $371^{\circ} \mathrm{C}$, respectively by pancaking

Fig. 3 shows the effect of pancaking before direct quenching on mechanical properties of steel A4 and F1. Tensile strength decreased by 65,175 , and $185 \mathrm{MPa}$ after as-quenching or tempering at 204 and $371^{\circ} \mathrm{C}$, respectively, with little change of impact energy in steel A4. And decreases of strength were $329,230,455 \mathrm{MPa}$ in steel Fl.

Fig. 4 shows the change of mechanical balance by pancaking El and G1 steels. Charpy impact energy increased by about 20 joules with little change in strength in both steels

Fig. 5. shows change of microstructure with processes in A3 steel. Austenite grain was equi-axed in $\mathrm{HR} / \mathrm{DQ}$ and elongated in CR/DQ while there were no ferrite grains at the austenite grain boundaries. Fig. 6 shows micro-structures of F1 steel. Austenite grain was equi-axed in HR/DQ and elongated in CR/DQ while there were ferrite grains at the austenite grain boundaries in CR/DQ and no ferrites in HR/DQ. 
Fig. 7 shows microsturctures of G1 steel. Austenite grain was equi-axed in HR/DQ and elongated in CR/DQ while there were no ferrite grains at the austenite grain boundaries.

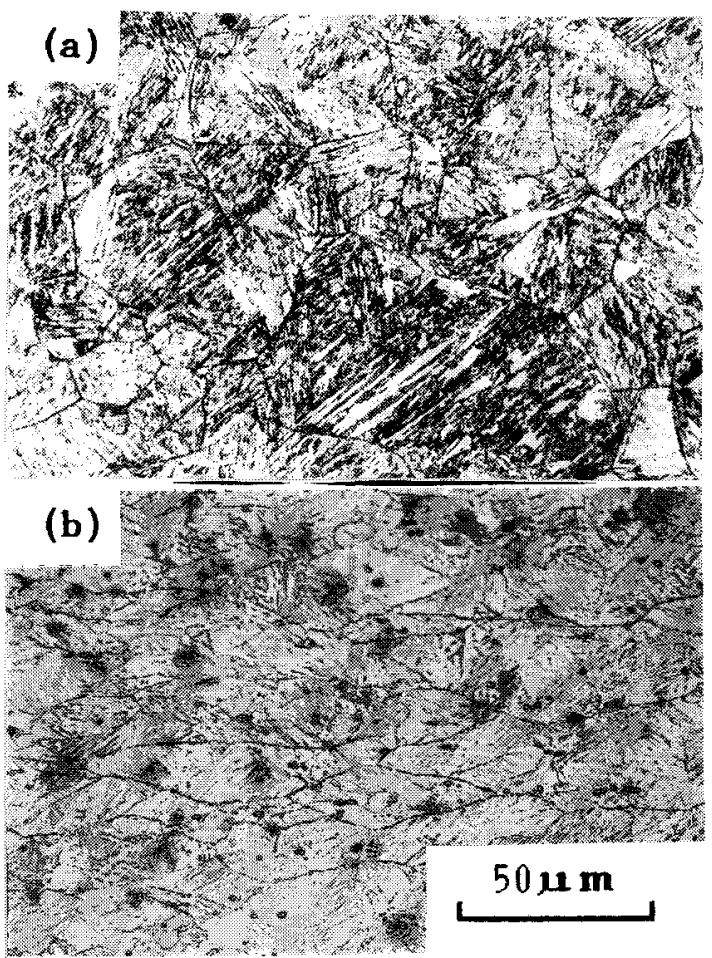

Fig. 5. Microstructures of $A 3$ steel. (a) $H R / D Q$, (b) CR/DQ
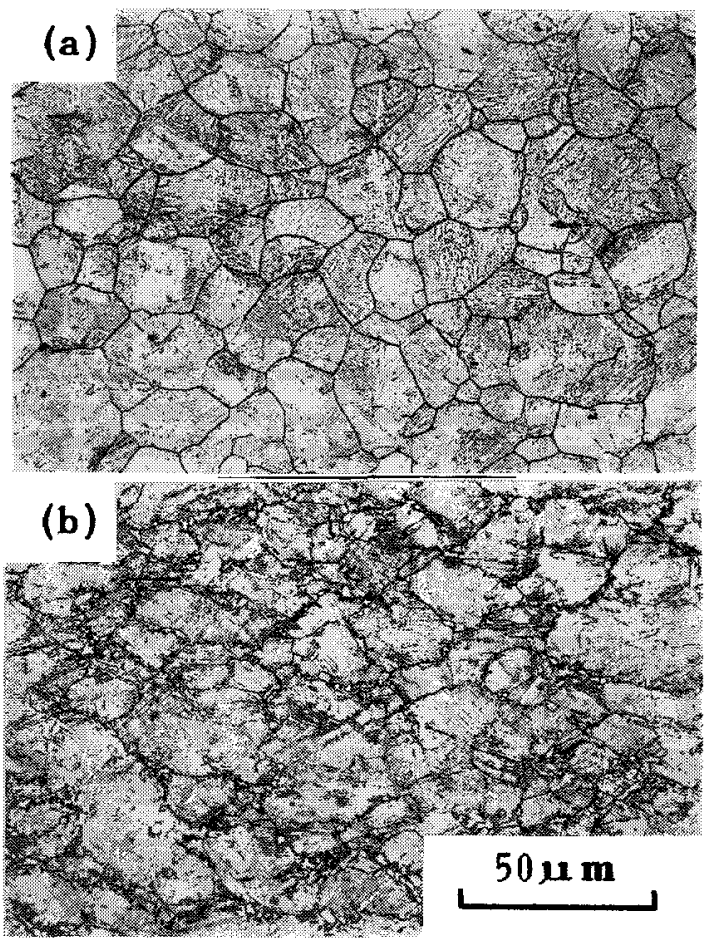

Fig. 6. Microstructures of $F 1$ steel. (a)HR/DQ, (b) CR/DQ
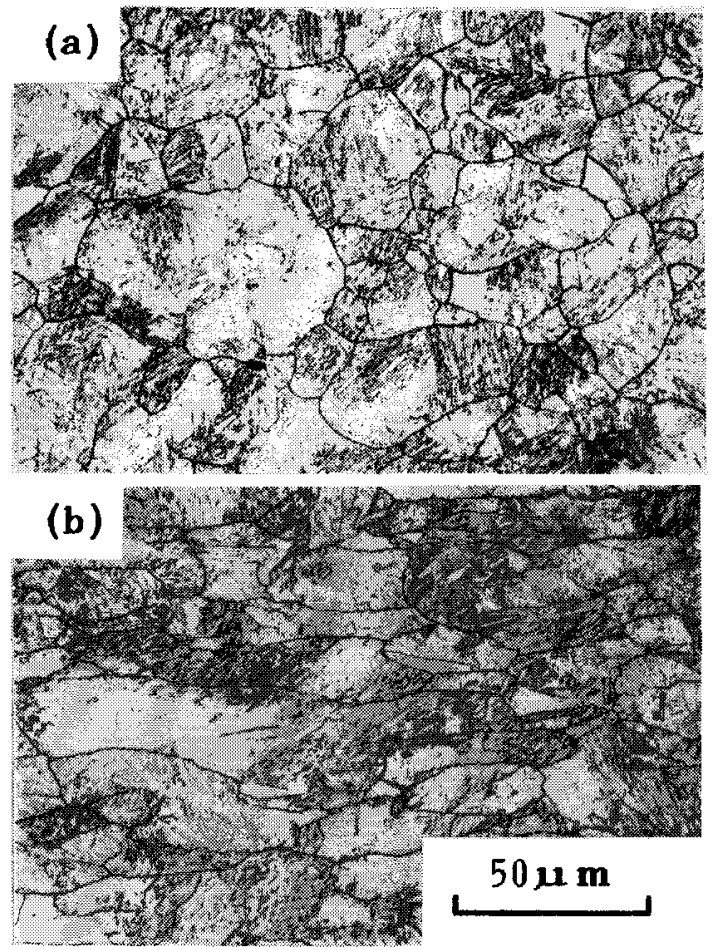

Fig. 7. Microstructures of $\mathrm{Gl}$ steel. (a) $H R / D Q$, (b) $C R / D Q$

Fig. 8, in which open mark stands for HR/DQ and solid mark for $\mathrm{CR} / \mathrm{DQ}$, shows change of hardenability by pancaking A3, A4 and F1 steels. Hardenability is evaluated by the temperature of $50 \%$ transformation (TT50\%) during cooling. TT50\% decreases as hardenability increases. And pancaking decreased hardenability, i.e. increased TT50\% by about $47^{\circ} \mathrm{C}$ from $493^{\circ} \mathrm{C}$ to $540^{\circ} \mathrm{C}$ at the cooling rate of $50^{\circ} \mathrm{C} / \mathrm{sec}$ in $\mathrm{A} 3$ steel containing $70 \mathrm{ppm} \mathrm{B}$ and $20 \mathrm{ppm} \mathrm{N}$. TT50\% was lower than $550^{\circ} \mathrm{C}$ at the cooling rates higher than $10^{\circ} \mathrm{C} / \mathrm{sec}$ even after pancaking in A3 steel. TT50\% of A4 steel containing $8 \mathrm{ppm} \mathrm{B}$ and $130 \mathrm{ppm} \mathrm{N}$ was between 600 and $650^{\circ} \mathrm{C}$ while that of F1 steel containing $0.58 \%$ Cr-18ppm B-90ppm N was between 550 and $600^{\circ} \mathrm{C}$. And pancaking also increased TT50\% of both A4 and F1 steels. Fig. 9 shows change of hardenability by pancaking E1 and G1 steels. TT50\% was lower than $550^{\circ} \mathrm{C}$ at the cooling rates higher than $10^{\circ} \mathrm{C} / \mathrm{sec}$ even after pancaking El steel containing $0.252 \%$ Mo. TT50\% was lower than $520^{\circ} \mathrm{C}$ at the cooling rates higher than $10^{\circ} \mathrm{C} / \mathrm{sec}$ even after pancaking Gl steel containing highest alloying contents such as $0.233 \% \mathrm{Mo}$ and $0.59 \% \mathrm{Cr}$.

\section{Discussion}

The effect of pancaking on mechanical balance can be classified into three groups. Pancaking increased strength without a change in impact toughness, as shown in Fig. 2, in the first group to which $\mathrm{A} 3$ steel belongs. Pancaking decreased strength without a change in toughness, as shown in Fig. 3, in the second group to which A4 and Fl steels 


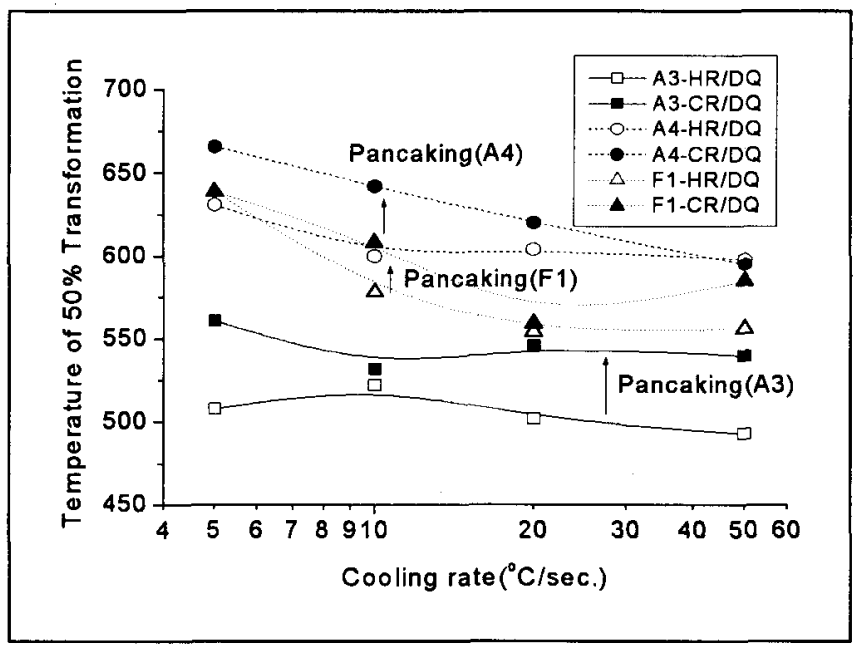

Fig. 8. Effect of Pancaking on temperature of 50 transformation in $\mathrm{A} 3, \mathrm{~A} 4$, and $\mathrm{F} 1$ steel.

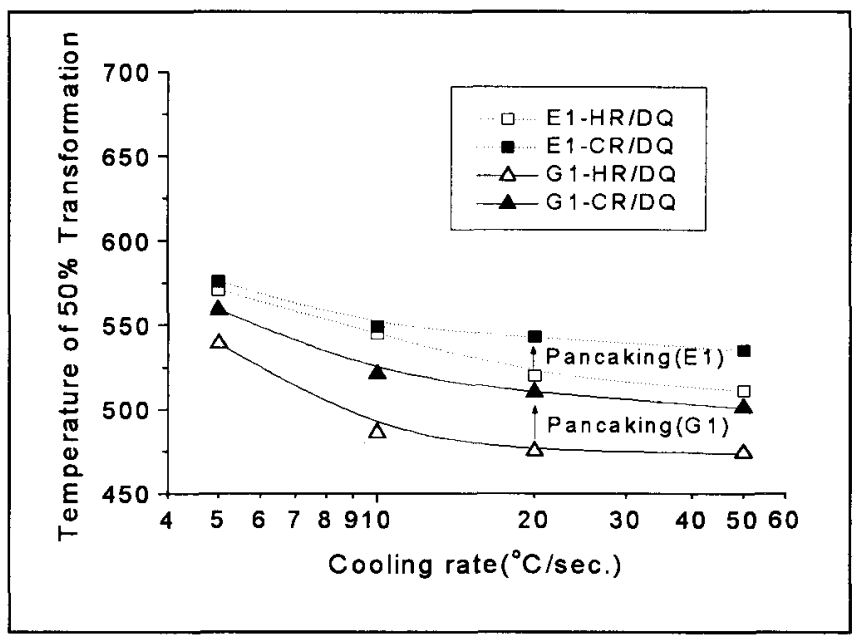

Fig. 9. Effect of Pancaking on temperature of 50 transformation in E1 and G1 steel.

belong. Impact toughness increased without a change in strength by pancaking, as shown in Fig. 4 , in the last group to which $\mathrm{El}$ and $\mathrm{Gl}$ steels belong.

When strength decreased by pancaking, there were ferrite grains at the austenite grain boundaries as shown in Fig. 6 for F1 steel. And TT50\% of A4 steel was higher than $600^{\circ} \mathrm{C}$ and that of $\mathrm{Fl}$ steel was higher than $550^{\circ} \mathrm{C}$ as shown in Fig. 8. And ferrite grains were observed in CCT specimens of A4 steel in all the cooling rates and process conditions with TT50\% higher than $600^{\circ} \mathrm{C}$. Meanwhile ferrite grains were observed in almost all CCT specimens of F1 steel except in HR/DQ simulation with cooling rate faster than $20^{\circ} \mathrm{C} / \mathrm{sec}$ showing TT50\% lower than $580^{\circ} \mathrm{C}$. Fl steel was expected to have a high hardenability due to $0.58 \% \mathrm{Cr}$ addition. But it had a lower hardenability than expected because of a high $\mathrm{N}$ content of $90 \mathrm{ppm}$, resulting in a decrease of effective $B$. From above results, it can be said that pancaking decreases strength due to formation of ferrite at the austenite grain boundaries when pancaking is applied to the steels of low hardenability with TT50\% higher than $550^{\circ} \mathrm{C}$.
When TT50\% were lower than $550^{\circ} \mathrm{C}$, pancaking improved mechanical balance by increasing strength(Group 1) or increasing toughness(Group 3). In Group 1 and 3, there were no ferrite grains at the austenite grain boundaries as shown in Fig. 5 and 7. And there were no ferrite grains in all CCT specimens of A3, E1, and G1 steels with high alloy determined hardenability. Consequently, effective grain size can be decreased by pancaking and fine grain size increases strength or toughness without decreasing strength due to the formation of ferrite at austenite grain boundaries.

There are many reports about increase of toughness with slight increase ${ }^{(2)}$ or slight decrease ${ }^{(3,4,5)}$ of strength by pancaking. And there are also reports about increase ${ }^{(6)}$ or decrease $^{(7)}$ of strength without change of toughness by pancaking. It can be said that there are various effects of pancaking on mechanical balance.

$\mathrm{H}$. Yoshinaga et al. reported that strength decreased by decreasing finish rolling temperature from $900^{\circ} \mathrm{C}$ to $800^{\circ} \mathrm{C}$ in HT60 and HT80 steels ${ }^{(7)}$. They explained that the decrease of strength is due to poor hardenability resulted from the strain induced by hot working in the non-recrystallized austenite region, resulting in the formation of ferrite. Their results and explanation are similar with our second group. HT580 and HT780 steels have relatively low alloying contents compared with steels of tensile strength higher than $1000 \mathrm{Mpa}$.

K.A. Taylor reported that strength increased while uppershelf Charpy impact energy and impact transition temperature decreased by pancaking before direct quenching A514 steel of $0.2 \mathrm{C}-0.6 \mathrm{Mn}-0.5 \mathrm{Mo}-\mathrm{B}$ with Ti:N ratio of $4{ }^{(8)}$ In this steel, added $B$ is effective in increasing hardenability due to high $\mathrm{Ti}: \mathrm{N}$ ratio, resulting in low transformation temperature lower than $520^{\circ} \mathrm{C}$.

Some authors ${ }^{(9,10)}$ reported that the effect of pancaking depends on hardenability indexed by calculated ideal diameter. Vicker's hardness increased by 30 from 360 to 390 in steel with a large diameter, and decreased by 30 from 340 to 310 in steel with a small ideal diameter by applying $30 \%$ of strain in non-recrystallized austenite region. But there was no change of hardeness by pancaking steel with middle ideal diameter. ${ }^{(9)}$ When ideal diameter is small, strength decreased and fracture appearance transition temperature(FATT) increased by pancaking. Meanwhile, when ideal diameter is larger than $12 \mathrm{~cm}$, strength increased and FATT decreased by pancaking ${ }^{(10)}$.

Hardenabilities of the steels of this investigation depend on $\mathrm{B}, \mathrm{Ti}$, and $\mathrm{N}$ in addition to $\mathrm{C}, \mathrm{Si}, \mathrm{Mn}, \mathrm{Mo}$ and $\mathrm{Cr}$. But B, $\mathrm{Ti}$, and $\mathrm{N}$ are not included in the equation to calculate ideal diameter. Consequently, we used an TT50\% instead of ideal diameter as an index of hardenability. And the effect of pancaking on mechanical balance can be categorized based on TT $50 \%$.

\section{Conclusions}

(1) Strength decreased due to ferrite formation at austenite grain boundaries by pancaking before direct quenching steels with low alloy-determined hardenability, showing temperature of $50 \%$ transformation(TT50\%) higher than $550^{\circ} \mathrm{C}$. 
(2) Strength or toughness increased due to fine effective grain size by pancaking before direct quenching steels with high alloy-determined hardenability, showing TT50\% lower than $550^{\circ} \mathrm{C}$.

\section{REFERENCES}

1) N.Komatsubara, S.Watanabe, and H.Ohtani: Tetsu-to-Hagane, 69(1983), 975.

2) K.A. Taylor and S.S. Hansen: Accelerated Cooling of Rolled Steel, Pergamon Press (1987), 85.

3) H.Nakao, R.Yamaba, K.Hattori, and M.Tanaka: Proc. Phase Transformations During the Thermal/Mechanical Processing of Steel, Vancouver, British Columbia, Canada(1995) 195.

4) A. Yoshie, M. Fujioka and K. Okamoto: Proc. $35^{\text {th }}$ MWSP, Pittsburgh, Pennsylvania,USA (1993) 363.

5) P. Heedman and A. Sjostrom: Scandinavian J. Metallurgy 11(1982) 233.

6) C.S.Lee and W.Y. Choo: Proc. Accelerated Cooling/Direct Quenching of Steels, Indianapolis, Indiana,USA (1997) 51.

7) H. Yoshinaga, S. Watanabe, N. Nito, N. Nakano and S.Suzuki: Chinese Society of Metals, Beijing (1985) 723.

8) K.A. Taylor: Proc. $32^{\text {nd }}$ MWSP, Cincinnati, Ohio (1990), 463.

9) M.Hashimoto and W.Takahashi: CAMP-ISIJ 9(1996) 1144.

10) K.Okamoto, A. Yoshie and H.Nakao: Proc. Physical Metallurgy of Direct-Quenched Steels, Chicago, Illinois, USA (1992) 339 . 